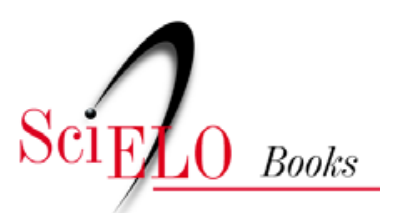

\title{
A criança e o sistema prisional
}

\author{
Cláudia Regina Vaz Torres
}

\section{SciELO Books / SciELO Livros / SciELO Libros}

TORRES, C.R.V. A criança e o sistema prisional. In: COELHO, M.T.Á.D., and CARVALHO FILHO, M.J., orgs. Prisões numa abordagem interdisciplinar [online]. Salvador: EDUFBA, 2012, pp. 161-177. ISBN 978-85-232-1735-8. Available from: doi: 10.7476/9788523217358.011. Also available in ePUB from: http://books.scielo.org/id/7mkg8/epub/coelho-9788523217358.epub.

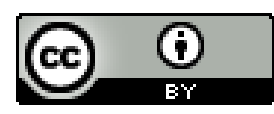

All the contents of this work, except where otherwise noted, is licensed under a Creative Commons Attribution 4.0 International license.

Todo o conteúdo deste trabalho, exceto quando houver ressalva, é publicado sob a licença Creative Commons Atribição 4.0.

Todo el contenido de esta obra, excepto donde se indique lo contrario, está bajo licencia de la licencia Creative Commons Reconocimento 4.0. 


\section{A criança e o sistema prisional}

Cláudia Regina Vaz Torres

\section{Introdução}

A construção de uma infância no entorno das prisões enquanto os pais, principalmente as mães, cumprem pena de reclusão revela que as crianças são cumpridoras solidárias deste encarceramento, uma vez que a dinâmica da vida dessas crianças passa a ser organizada em torno do familiar encarcerado. Carência afetiva e material constante, insegurança e invisibilidade social são apenas aspectos particulares dessa vivência.

As crianças possuem as suas percepções sobre o cumprimento da pena de reclusão do pai e/ou mãe e revelam as suas competências de interpretação acerca da sua realidade social, da prisão, do crime, da dinâmica familiar e das suas perspectivas de vida. Acrescenta-se que o itinerário de cada criança no sistema penitenciário durante o cumprimento da pena de reclusão do pai e/ou mãe é individual, privado e singular; entretanto, as condições de invisibilidade, como sujeitos de direitos, marcam esse percurso e repercutem no seu desenvolvimento e construção da infância.

As condições heterogêneas dessas crianças em relação ao mundo acentuam ao mesmo tempo a diferença e a marca identitária de filho de presidiário que delineiam olhares, interrogações, lugares e conceitos e, surpreendemente, também evidenciam o que escapa à objetivação, ao controle das instituições e ao que foi instituído. A análise da cons- 
trução de uma infância no entorno do contexto de reclusão do familiar revela, provoca, inquieta para pensar o que elas dizem sobre os seus modos de ser criança a partir da realidade que vivem.

Analisar as percepções das crianças que vivenciam a experiência de ter o pai e/ou mãe submetidos à custódia do Estado e as repercussões do sistema prisional na construção das suas identidades, evidenciando o papel do Abrigo para ressignificar os efeitos dessa experiência é a proposta deste artigo, tendo como referência a experiência como psicóloga de uma unidade prisional da Secretaria da Justiça, Cidadania e Direitos Humanos há mais de 12 anos.

Este trabalho resultou de uma pesquisa de doutorado do Programa de Pós-graduação em Educação da Universidade Federal da Bahia realizada entre 2007 a 2010, que se sustentou no percurso teórico e metodológico que concebe a complexidade da vida social das crianças através das suas percepções, ações e interpretações sobre a própria realidade, cujos objetivos foram alcançados através de um estudo de caso que se aproximou do estudo de caso do tipo etnográfico. A escolha por esse tipo de abordagem foi decorrente da complexidade da temática, na qual dimensões psicológicas, sociais e éticas constituíam a realidade, a dinâmica e o movimento das relações existentes no grupo de crianças dos contextos de desenvolvimento estudados.

Constatou-se que existem diferentes posições sobre a entrada e permanência de crianças nas unidades prisionais. Enquanto alguns pais se queixavam do pouco tempo de convivência com a família e da impotência que o encarceramento impõe, tornando-os espectadores do rumo que vai tomando a vida dos seus filhos, outros preferiam não receber os filhos nas visitas a fim de preservá-los e outros prometiam rebeliões diante da possibilidade da proibição da entrada de crianças nas unidades.

Evidenciou-se que as crianças que visitam o pai nos finais de semana convivem com essa realidade e passam silenciosas e invisíveis aos olhos do Estado pelos corredores e celas das unidades prisionais. Muitas delas não ficam isentas às consequências nefastas dessa vivência, principalmente aquelas que enfrentam a violação dos seus direitos, pois podem tornar-se objeto de uso, troca e meio de facilitação para entrada de material indevido - drogas, objetos perfuro-cortantes, etc. - nas unidades. As crianças são vulneráveis à condição do familiar 
dentro da penitenciária, pois o delito cometido pelo mesmo constitui marcas identitárias que possibilitam o reconhecimento entre eles no sistema penitenciário e proporcionam o estabelecimento de relações hierárquicas. Estas marcas demarcam lugares e evidenciam mecanismos de intimidação, controle e vigilância. (TORRES, 2010)

Diante dessa realidade em que as crianças entram, permanecem e constroem as suas infâncias, visitando o familiar, pretende-se discutir a construção do conceito de infância através dos estudos da Sociologia da infância (MONTANDON, 2005; SARMENTO, 2002; 2007) e o conceito de identidades será tratado na perspectiva dos estudos de Vigotski (1998; 2002), Ciampa (1986) e Woodward (2000), entre outros.

\section{Construindo os conceitos de infância e identidades}

A infância é analisada a partir dos estudos da Sociologia da infância (SARMENTO, 2002; 2007) que trata da criança como um sujeito de direitos, que abarca em si proteção e participação social nos diferentes e desiguais modos de construção de infâncias. Considera-se assim o lugar que a criança ocupa nas diferentes organizações sociais, pois os diferentes modos de ser e agir da criança são construídos na interação com as pessoas, nos discursos e nas diversas expectativas sobre os modos de subjetivação desse sujeito.

A concepção da criança como um sujeito de direitos é recente, inaugurou-se com a Modernidade, mas efetivamente expressou-se como instrumento legal e normativo em 1990 com o Estatuto da Criança e do Adolescente. (BRASIL, 1990)

Deste modo o conceito de infância, neste estudo, além de contemplar o que está posto no Estatuto da Criança e do Adolescente (ECA) (BRASIL, 1990) considera a infância como um processo social, histórico e cultural que transcende e transforma a realidade a partir das experiências e das construções simbólicas de cada pessoa na interação com o outro, distanciando-se da ideia de infância como um processo puramente linear e natural que se desdobra em etapas sucessivas e evolutivas. A construção da infância tem a sua dialeticidade, que se entrecruza com pessoas, crenças, leis, lembranças, sonhos e desejos. 
Os estudos atuais sobre a infância partem dos estudos da criança a partir delas mesmas, descortinando a realidade social que emerge das interpretações infantis sobre os seus mundos. Essa ideia rompe com a tradição na Sociologia e assume as crianças como atores sociais que agem no contexto social e constituem-se sujeitos através de processos de adaptação, interiorização, apropriação, reprodução e reinvenção de si. Os seus modos de agir, pensar e relacionar-se constituem processos de construção de identidades que participam na estruturação das suas ordens sociais.

Conhecer as crianças impõe, por suposto, conhecer a infância. Isto vale por dizer que os itinerários individuais, privados e singulares de cada criança só fazem completo sentido se perspectivados à luz das condições estruturais que constrangem e condicionam cada existência humana. Essas condições, relativamente a cada categoria geracional, constituem o pano de fundo sobre o qual intervém cada um dos actores, ou, dito de modo mais rigoroso, exprimem o conjunto de constrangimentos estruturais que cada membro da sociedade continuamente sofre, interpreta, reproduz e refaz na sua interacção com os outros. (SARMENTO, 2002, p. 4)

Desse modo, nos processos de subjetivação e na construção das identidades das crianças, concorrem processos múltiplos e permanentes que produzem diversos modos e estilos de existência. Os processos de construção de identidades dão-se incessantemente em diversos lugares e no confronto com as normas que prescrevem os modos como a pessoa deve ser e se comportar em relação a um conjunto de valores.

As identidades estão associadas à participação em uma categoria ou grupo que envolve significados ou estereótipos. Desse modo, ao assumir uma identidade, há uma pressão social para aceitação dos significados ou estereótipos como pertencentes ao sujeito e autodescritivos.

Woodward (2000) ao analisar como as identidades são construídas, sugere que elas são formadas em comunhão com outras identidades. As identidades são, pois, construções que aparecem sob a forma de oposições binárias, mas acentuando os traços da diferença na sua constituição. A identificação é, pois, um processo de articulação, uma suturação, uma sobredeterminação, e não uma subsunção, não há nunca um ajuste completo, uma totalidade. Como todas as práticas de significação, ela está sujeita ao jogo da différance. 
Entende-se que, para explicar os processos de identificação, não há um ponto fixo e permanente, como também não há uma essência última e universal. Considerações teóricas no campo da Psicologia, através dos estudos de Ciampa (1986), contribuem para ampliar a compreensão do processo de construção das identidades, como um fenômeno social, um processo em constante movimento dialético, construído pela atividade e ação do sujeito, através da articulação de igualdades e diferenças que constituem a história pessoal. Ciampa (1986) explica que ela aparece como um processo, sem características de permanência ou independência entre os elementos biológicos, psicológicos e sociais que a constituem.

Para a análise da condição da construção das identidades das crianças, importa conhecer aspectos do Sistema Penitenciário, suas políticas, relações e desdobramentos e os contextos do desenvolvimento das crianças: as visitas e o Abrigo que acolhe os filhos dos internos.

\section{Crianças, famílias e sistema penitenciário}

Os sistemas penitenciários são instrumentos de aplicação da pena. A pena imposta a quem comete um crime tem um caráter retributivo e preventivo, possui como caracteres atingir o autor do crime, ter sua aplicação disciplinada pela lei e ser proporcional ao crime.

De acordo com Foucault (1987), é um conjunto complexo que reúne além de regulamentos coercitivos, programas correcionais para a delinquência.

Com a instituição da Lei de Execução Penal n ${ }^{0}$ 7.210, de 11 de julho de 1984 (BRASIL, 1984) e depois de elaboradas as Regras Mínimas para o Tratamento do Preso no Brasil, atendendo à determinação da Assembleia Geral da ONU, preceituada pela Resolução n ${ }^{\circ} 2.858$, de 20 de dezembro de 1971 e reiterada pela Resolução n ${ }^{\circ} 3.218$ de 6 de novembro de 1974, foram construídas orientações sobre os limites para a punição dos presos. Entretanto, o sistema penitenciário brasileiro ainda pode ser caracterizado pela ausência de condições dignas de vida que se traduz pelo empilhamento de pessoas em celas com capacidade ultrapassada, falta de higiene, ar, luz, alimentação adequada, acesso deficiente à assistência jurídica e médica, ócio forçado e distanciamento 
da família. Assiste-se na maior parte das penitenciárias brasileiras a difusão da tuberculose, vírus HIV e escabiose, naturalização da violência, sob a forma de extorsões, maus-tratos, estupros, assassinatos, exclusão e escorraçamento de homens - apelidados de fariseus no Estado da Bahia - e mulheres desprovidos de algum dinheiro e apoio familiar.

Ao sistema carcerário que objetiva aplicar sanções aos atos desviantes e conter os distúrbios urbanos no Brasil é acrescido, na análise de Wacquant (2001, p. 11), sociólogo francês que estudou o sistema carcerário e judicial, o estado das prisões do país.

[...] que se parecem mais com campos de concentração para pobres ou com empresas públicas de depósito industrial dos dejetos sociais, do que com instituições judiciárias servindo para alguma função penalógica - dissuasão, neutralização ou reinserção. O sistema penitenciário brasileiro acumula com efeito as taras das piores jaulas do Terceiro Mundo, mas levadas a uma escala digna de Primeiro Mundo por sua dimensão e pela indiferença estudada dos políticos e do público [...].

Depreende-se com o autor que o sistema carcerário brasileiro é assentado na dominação. No Brasil, o Estado Penal foi desenvolvido para controlar as desordens suscitadas pela pauperização do proletariado urbano, pela desregulamentação da economia, pela ausência de programas sociais, pela retração de programas sociais, pela dissimulação e indiferença nas relações humanas e pela dessocialização do trabalho assalariado, estabelecendo uma "[...] ditadura sobre os pobres [...]”. (WACQUANT, 2001, p. 10)

Para Wacquant (2001), a prisão na contemporaneidade possui fundamental importância na manutenção de uma política neoliberal, pois representa a ameaça da punição, o controle dos desvios e produz subjetividades punitivas que realimentam a necessidade da prisão para controlar os pobres. Na sua análise, o crime está atrelado a questões econômicas; entretanto existem tipos penais caracterizados por relações sociais, sem qualquer cunho econômico ou em que as questões econômicas ocupam um lugar secundário, como, por exemplo, o crime contra a vida: homicídio, lesão corporal, entre outros.

Nesse sistema carcerário, durante as visitas, a criança vivencia, assim como o seu pai e/ou mãe reclusa, as consequências das barreiras colocadas pela instituição que separam a vida cotidiana da pessoa interna do mundo externo, convive com os diferentes discursos formulados 
sobre a prisão e os discursos que vêm da prisão, enfrenta a convivência com modelos que cometeram crimes e experimentam a subordinação, exclusão social e vivenciam situações em que se vêem como diferentes. Há uma submissão aos elementos constituintes da prisão e uma identificação da(o) reclusa(o) a um lugar, um posicionamento como pessoa, embora, algumas vezes, a pessoa interna tenha consciência de que essa posição está em conflito com outros modos assumidos por ela. A(o) reclusa(o) é convocada(o) a ocupar outras posições como meio de resolução de conflitos e, assim, as contradições são apresentadas, pois o modo de ser deste sujeito difere do modo como ele se posiciona para ser aceito pela massa carcerária e para sobreviver. As identidades são construídas a partir de negociações.

Constatou-se em pesquisa realizada durante o Mestrado (TORRES, 2004) que, na penitenciária, a convivência entre os presos num ambiente de privação e maus-tratos gera agressões e brigas. Além de haver repressão por parte do sistema, que isola e priva da liberdade como medida punitiva, há também repressão por parte dos outros reclusos que atuam de acordo com um código de conduta interno, elaborado por eles e perpetuado ano após ano. A depender do crime cometido, estupro ou infanticídio, o sujeito fica estigmatizado, pode ser rebaixado e ter que prestar serviços, tais como: lavar, limpar, ceder a sua comarca (espaço de deitar) e dormir junto ao vaso sanitário, oferecer-se sexualmente, etc. aos demais internos, sofrer desprezos e agressões. Os que escapam das humilhações são aqueles que contam como o auxilio principalmente financeiro, da família. O que "perdem do psicológico”, conforme dito por um recluso na ocasião das entrevistas, é que, em função dos conflitos travados entre eles, para ter uma convivência sem tantos atritos, passam a assumir identidades de acordo com os apelos feitos pelos lideres da população carcerária.

Na prisão, o delito cometido constitui marcas identitárias que possibilitam o reconhecimento entre eles no sistema penitenciário e proporcionam o estabelecimento de relações hierárquicas. Estas marcas estão nas paredes das celas, nas grafitagens nos muros, nos corpos tatuados, mutilados e adornados, nas roupas que demarcam os territórios e evidenciam mecanismos de intimidação, controle e vigilância. Estas marcas denunciam ainda os maus tratos, histórias e passagens pelo cárcere. 
Compreende-se que uma prisão é constituída pelas relações que são estabelecidas, o modo como são travadas e negociadas a permanência no lugar, os sentidos da prisão pela sociedade e todos os processos de exclusão vivenciados. Como analisa Foucault (1979), além das decisões, regulamentos que são elementos constituintes da prisão, existem as estratégias, astúcias que não são de ninguém, mas que são, no entanto, vividas, assegurando o funcionamento e a permanência da instituição.

Neste espaço, as crianças passeiam e constroem as suas infâncias, visitando o familiar recluso por diferentes períodos de tempo.

Quanto às visitas, a Lei de Execução Penal de 11 de junho de 1984 (BRASIL, 1984) estabelece que o interno tem direito a visitas semanais. O Conselho Nacional de Política Criminal e Penitenciária (CNPCP, 2007) no Novo Plano Nacional de Política Penitenciária pretende aperfeiçoar o controle das visitas, particularmente as íntimas, em lugares apropriados, como também os procedimentos para a revista da pessoa reclusa, visitantes, servidores ou prestadores de serviços.

A visita, com todas as limitações de tempo e espaço, promove a integração, o contato, o acolhimento, o sentimento de pertencimento a uma outra realidade além do muro. A visita induz a participação dos familiares no cumprimento da pena de reclusão e em algumas situações na responsabilização e no fracasso.

Entende-se que com a mulher há uma dependência emocional em relação ao homem e os valores de uma vida marginalizada não permitem o afastamento. Mães e mulheres, além de visitar o homem recluso, trabalham para ele e por ele, prostituem-se, se necessário for, com outros presos, a fim de garantir a vida ou vantagens, reivindicam melhores condições prisionais, expõem-se a todo tipo de prática delituosa para ajudá-lo. (TORRES, 2004) Em contrapartida, a maioria das mulheres reclusas é abandonada pelo companheiro e recebe pouco ou nenhum apoio da família. Quando recebe visitas é do companheiro que, também, está preso ou do namorado que conseguiu arrumar depois do aprisionamento, através das outras mulheres reclusas que possuem companheiros presos nas outras unidades.

Para visitar o pai e/ou mãe reclusa a criança é submetida à fila na entrada e ao procedimento da revista corporal. A revista ou busca corporal nos familiares dos internos é um dos procedimentos de segurança 
nos estabelecimentos penais que tem um caráter preventivo, uma vez que objetiva impedir o ingresso de celulares, armas ou drogas no ambiente carcerário. Para a realização da revista direta sobre o corpo do indivíduo, o Conselho Nacional de Política Penitenciária (CNPCP) no Art. $2^{\circ}$ exigiu a existência da fundada suspeita de que o indivíduo é portador de objeto ou substâncias proibidas; assim, apenas quando há suspeita é autorizada a revista direta, manual e superficial no corpo e na roupa do revistado. Na verdade, o que ocorre cotidianamente nas visitas é a imposição da revista direta, não havendo qualquer observância do artigo supracitado. Acrescenta-se que não foram estabelecidos os limites da revista manual pelo CNPCP, possibilitando que em algumas ocasiões o agente efetue uma intervenção no corpo da pessoa revistada, tocando-a nas partes íntimas e, com isso, cometendo excessos e arbitrariedades.

Os familiares encontram saídas para os impasses e constrangimentos suscitados pela visita ao familiar, como também desenvolvem habilidades para resolver problemas pontuais, como: conflitos do interno com o ambiente do cárcere, angústias pelo tempo da prisão, falta de dinheiro, queixas em relação a um membro da família e ainda acolher e criar a esperança que pode ajudar o(a) recluso(a) a encontrar novos lugares no sistema onde ele está inserido e no retorno à vida social. A família, então, assegura a relação da pessoa reclusa com o social, auxiliando na preservação do seu bem-estar.

Entre os homens reclusos, a mesma posição de poder e privilégio ocupada pelos líderes é conferida aos seus familiares dentro e fora do sistema penitenciário. Assim, nas visitas, as celas são desocupadas para receber a companheira, filhos, etc., e os demais ocupam a área externa (o pátio) com a construção de tianas que permitem o encontro íntimo. A pessoa reclusa que goza de uma posição hierárquica tira proveito de sua situação e estabelece uma relação de dominação para com os demais reclusos, chegando inclusive a proibir a entrada de uma visita se esta desagrada às lideranças.

Além do momento das visitas às unidades prisionais, a entrada e permanência no Abrigo durante o cumprimento da pena de reclusão do familiar será destacada. 


\section{Centro educativo nova semente: um lar simbólico para filhas(os) das(os) internas(os)}

O Centro Educativo Nova Semente (Abrigo/Creche), dirigido pela Fundação Dom Avelar Brandão, vinculada à Arquidiocese de Salvador e à Pastoral Carcerária funciona há onze anos abrigando bebês e crianças em regime de internato numa área desmembrada do Complexo Penitenciário da Mata Escura. O Abrigo é mantido por convênios federais, estaduais e municipais e doações. Outras crianças, filhos de internos(as) têm atendimento diário e são assistidas com reforço escolar e atividades de estímulo à cidadania. As crianças mais velhas estão matriculadas nas escolas públicas e particulares do bairro e as crianças pequenas frequentam a Creche Nova Semente.

O cotidiano do Abrigo seguindo princípios morais e assistenciais tem como papel acompanhar e direcionar a entrada da criança, a adaptação e permanência, a construção de modos de ser e viver, a manutenção dos vínculos familiares e o retorno ao lar. Identificou-se que acolher e formar hábitos de conduta consiste em disciplinar, assumir atitudes firmes para controlar gestos e impulsos, orientar pelo exemplo, oferecer adequadas condições de vida e submeter afetos e corpos à regulamentação moral. (FOUCAULT, 1987)

As crianças convivem durante as visitas ${ }^{1}$ com o ambiente carcerário que institui uma relação poder-saber para manter o controle e moldar corpos, linguagem e comportamentos (FOUCAULT, 1988), mas para muitas dessas crianças o que prevalece não é o contexto prisional e, sim, o contato afetivo com a mãe. As meninas e meninos idealizam a mãe e identificam-se com as mesmas, principalmente porque é com elas que mantêm um vínculo afetivo. Acreditam que as suas mães não cometeram crimes ou, quando admitem que houve um delito, minimizam a ocorrência e protegem a mesma, tomando-a como vítima. As crianças expressam o quanto as mães estão continuadamente envolvidas na tarefa de assumir os seus cuidados.

O Abrigo é um importante contexto de acolhimento e educação dessas crianças. Os discursos, principalmente religiosos e morais sobre

1 Acrescenta-se que as crianças do Abrigo Centro e Nova Semente não passam pela revista íntima. 
a prisão, o crime, a punição, entre outros, cruzam-se com processos de exclusão, situações estigmatizadoras e tragédias familiares que criam sentidos e efeitos nas construções subjetivas de meninas e meninos. É um processo que sempre é atualizado à medida que entra uma nova criança na instituição. As profissionais do Abrigo apontam saídas distantes dos muros do sistema penitenciário e ampliam as expectativas de uma vida diferente da mãe e/ou pai recluso, a ser começada.

\section{Identidades: crianças e filhos de presidiários}

A construção da identidade das crianças no contexto de ter um pai e/ou mãe presa é conflitante, primeiro porque precisa ver e sentir a situação de aprisionamento e punição do familiar, segundo por conviver num contexto de institucionalização, quando são abrigadas durante o cumprimento da pena de reclusão e terceiro pela condição de pertencer a um grupo: filhos de presidiários.

O crime e a punição são, então, aspectos importantes nos processos de subjetivação e identificação dessas crianças, mas que não definem a trajetória de vida desses meninos e meninas. Assim, o crime, a situação de aprisionamento e punição do familiar, afastamento familiar, abrigamento e ser filho de presidiário são fatores difíceis para uma criança analisar, sustentar, interpretar e conviver, porém não determinam a entrada na vida criminal, semelhante ao ocorrido com o seu pai e/ou mãe reclusa.

Uma educadora no seu depoimento reforça que, "Foi uma realidade triste ver as crianças no cárcere. Foi um choque. Tem que vir a educação para trabalhar isso. Não penso que porque tem um pai lá dentro elas serão aquilo também. Isso não”. (E1, m).

Constatou-se neste estudo que a criança diz quem é através do que conta sobre o fazer do seu pai e/ou mãe, aspecto importante na análise da construção das identidades. Para Ciampa (1986), a criança antes de nascer já é representada como filho de alguém e essa representação prévia o constitui efetivamente e objetivamente como filho e membro de uma determinada família. Posteriormente, essa representação é interiorizada pelo indivíduo e reafirma-se à medida que as relações nas quais estiver envolvido confirmarem essa representação, através de comportamentos e discursos que reforcem a sua 
identificação com o fazer do pai e/ou mãe e com tudo que envolve a dinâmica familiar.

A identificação de uma criança como filho de um presidiário(a) é pressuposta; no percurso relacional, os comportamentos vão ocorrer como consequência das relações e, também, como condição. A criança se vê, identifica-se como filho de presidiário ou filho de um ladrão, etc., é identificado com tal e interpreta, ao seu modo, este dado da sua realidade. Como analisa Ciampa (1986), a posição de um sujeito o identifica, discriminando-o como dotado de certos atributos, de predicações, que dão uma identidade considerada formalmente como atemporal. A construção dessa identidade deixa de ser vista como uma sucessão temporal, passando a ser vista como manifestação de um ser sempre idêntico a si mesmo na sua permanência e estabilidade. Então para estas crianças, essa posição produz uma submissão a essa identidade, a esse lugar, promove uma estabilidade.

Então, recorre-se ao autor para destacar que, na questão da identidade das crianças, evidencia-se a diferença e a igualdade. Por fazerem parte de uma família específica, são identificados como se possuíssem as mesmas características. A compreensão sobre a construção da identidade envolve os significados implícitos e o que é aparente diante de uma ação realizada. Assim, o crime é a atividade realizada que se coisifica pela predicação. O tipo de crime marca o sujeito, tem poder sobre o indivíduo, mantém e reproduz sua identidade, mesmo que seja algo ocorrido no passado. Quem comete um crime recebe uma identificação pelo tipo de crime que cometeu e, ao ser punido, recebe uma outra identificação que passará a portar. É desse lugar e duplo estigma que pai e/ou mãe carregam que uma criança se constrói. As pessoas vão se constituindo umas às outras, ao mesmo tempo em que constituem um universo de significações que as constituem. As identidades envolvem a articulação de várias personagens, articulação de igualdades e diferenças atravessada por uma história pessoal.

Através de conflitos, crises e rupturas do sujeito com o meio, as identidades são interpretadas, negociadas e construídas.

Os depoimentos de técnicas do Abrigo sobre as crianças confirmam:

"A criança tem uma idealização com o pai, tem uma identificação com ele a ponto de realizar atividades [...] ela diz que vai ser médica e 
outras vezes, diz que vai ser chefe como o pai que é chefe dos presos”. $(\mathrm{T} 3, \mathrm{~m})$

"Uma criança disse numa entrevista para um documentário que era um menor infrator. Ele associou que se a mãe estava presa então ele era um menor infrator. Depois as crianças ficaram repetindo e ele disse que não sabia o que era menor infrator [...]”. (T2, m)

Depreende-se que os significantes: prisão, crime e infrator são formados por representações e práticas sociais discursivas que demarcam e atribuem sentidos às identidades dessas crianças. Esta vivência produz marcas simbólicas que possibilitam a construção de um lugar, no qual cada um pode identificar-se e construir a sua história. O último depoimento traz o termo "menor infrator". Menor infrator foi uma identidade que a criança atribuiu a si mesma e que está de acordo com a posição da sua mãe na sociedade por ter cometido um ato delituoso. A percepção de que a má conduta da mãe e a marca identitária associada ao crime e à prisão pertencem também ao filho demonstra a concepção de que o envolvimento com a criminalidade é transmitido de mãe e/ou pai para filho, tornando as crianças alvo de preconceitos e estigmas. Este estigma, conforme depoimento, de algum modo irá mediar as relações estabelecidas por esta criança com o mundo, pois as marcas do preconceito e exclusão estarão presentes no seu processo de subjetivação.

A identidade, então, como explica Ciampa (1986), é representada por um nome, sobrenome e também abre as condições para que outras representações sejam ditas, porque serve como respostas, como a atividade que realiza. Assim, diante da pergunta da pesquisadora à criança sobre quem ela é, há implicitamente a idéia de que existem respostas que a identifiquem como pessoa. É através da atividade de mãe infratora que o menino evidencia a sua identidade, diz quem ele é.

Constatou-se, também, que a criança sofre mais com a prisão da mãe. Nas entrevistas e observações realizadas durante a pesquisa de campo, as educadoras relataram que as crianças não se importam em falar que o pai está preso e o tipo de delito, mas que quanto à mãe custodiada, explicam sempre que a mesma viajou e sentem-se ofendidas quando a genitora é alvo de comentários ou brincadeiras de outras crianças. Segundo depoimentos, as mães são percebidas pelas crianças de modo diferente do pai. A relação da criança com o pai que comete 
um crime, principalmente homicídio e não se desvinculou da família, é de respeito. Quanto à mãe, como não é esperada na nossa cultura a participação e iniciativa da mulher na criminalidade, as crianças sentem vergonha em falar sobre o assunto, ou até mesmo visitá-las.

A visão idealizada que eles têm da mãe sofre um impacto em razão da constatação de que ela se posiciona completamente diferente do que é proposto socialmente para mulheres e homens como fazendo parte da "natureza" feminina; então, vê-la reclusa por conta de um crime que cometeu provoca, entre outros sentimentos, como culpa: dor, vergonha e distanciamento. Então, para essas crianças, falar da mãe presa ou da mãe que cometeu um crime é falar de si mesmas, pois se o modelo não é aceito socialmente, o delas também não será. A naturalidade com que tratam do pai transgressor representa o papel de gênero que mulheres e homens construíram. A mãe é a pessoa mais importante para a criança, é o vínculo mais forte, enquanto o pai como membro da família tem um papel secundário. As ações que o pai realiza não repercutem do mesmo modo na construção identitária da criança como aquilo que a mãe faz.

As crianças internalizaram a partir das suas relações com a cultura que ser mãe é maternar, cuidar da casa, dos filhos e, em algumas situações, do marido. Marcada fundamentalmente para assumir como atribuição a tarefa de orientar filhos e filhas, a manter um lar harmonioso, livre de distúrbios e ser responsável pela educação moral dos jovens (LOURO, 1999, 2003), a mãe, numa situação de aprisionamento, rompe com esses valores construídos socialmente.

Diante dessa condição, meninas e meninos conflitam com os parâmetros a serem seguidos na construção das suas identidades, pois possuem o exemplo de sua mãe transgressora e relacionam-se com pessoas no mundo social que evidenciam o papel de mãe como exemplo de perfeição moral, educação, docilidade e vida sacrificada para dar conta das suas tarefas no âmbito público e privado, sem negligenciar nenhum deles. Resta, então, para as crianças, o silêncio sobre o destino das suas mães em razão do crime cometido e a passagem pelo cárcere.

Todavia o silêncio da criança não minimiza os processos que ocorrem internamente, que envolvem a articulação da igualdade (equivalências) e diferenças que vão implicar em posições no mundo. No cotidiano, manifestam-se os desdobramentos das múltiplas deter- 
minações a que se está sujeito. Como analisa Ciampa (1986), uma rede intricada de representações permeia todas as relações, na qual cada identidade reflete outra identidade. Há um jogo de reflexões múltiplas que estrutura essas relações da criança com a mãe transgressora, com o crime, o sistema prisional e a sociedade e que é mantida pelas atividades dos indivíduos envolvidos.

A criança conflita com essa identidade da mãe transgressora, uma vez que essa identidade surge também como uma representação dela no mundo na relação com o outro. Distanciar-se desse lugar de transgressor é um movimento singular de cada criança ao perceber que o outro pode identificá-lo como idêntico a sua mãe - dotado das mesmas predicações - e vir a sofrer as consequências desse processo; como também envolve ocultar partes e aspectos relacionados à própria história - com a qual pode se identificar e ser identificada - para poder ser aceito.

Outras crianças podem não conflitar com a identidade de mãe transgressora e permanecerem coladas a esse lugar, identificando-se, sendo identificadas, desempenhando papéis decorrentes dessa posição e repondo sempre no presente a marca da transgressão.

Desse modo, como seres sociais, meninos e meninas têm um horizonte de possibilidades de construção das suas identidades, desdobram-se reflexões e ações que transformam o cotidiano dessas crianças e constroem as subjetividades e identidades que se traduzem em desejos, projetos, tendências, entre outros.

As crianças que convivem com o contexto do cárcere agem no contexto social, são competentes para perceber a sua realidade e buscar um ponto de apoio para enfrentar a lógica do silêncio e submissão que ordena o sistema prisional.

\section{Referências}

BRASIL. Lei $n^{\circ} 7.210$, de 11 de julho de 1984. Institui a Lei de Execução Penal. Diário Oficial [da] República Federativa do Brasil, Brasília, DF, 12 jul. 1984. Disponível em: <http://www.planalto.gov.br/ccivil_03/Leis/ L7210.htm>. Acesso em: 01 jun. 2009.

BRASIL. Lei $n^{\circ}$ 8.069, de 13 de julho de 1990. Dispõe sobre o Estatuto da Criança e do Adolescente e dá outras providências. Diário Oficial [da]

República Federativa do Brasil, Brasília, DF, 14 jul. 1990. Disponível em: 
$<$ http://www.planalto.gov.br/ccivil_03/leis/L8069.htm>. Acesso em: 01 maio 2009.

CNPCP - CONSELHO NACIONAL DE POLÍTICA CRIMINAL E PENITENCIÁRIA. Novo plano nacional de política penitenciária. Brasília, 2007. Disponível em: <http://www.carceraria.org.br/fotos/fotos/admin/ Sistema\%20Penal/ Sistema\%20Penitenciario/NOVO_PLANO_NACIONAL_ POLITICA_PENITENCIARIA_2007.pdf $>$. Acesso em: 01 maio 2009.

CIAMPA, Antonio. A estória do Severino e a história da Severina. São Paulo: Brasiliense, 1986.

FOUCAULT, Michel. Microfísica do poder. Rio de Janeiro: Grall, 1979.

. História da sexualidade. Rio de Janeiro: Graal, 1988.

. Vigiar e punir: nascimento da prisão. Petrópolis: Vozes, 1987.

LOURO, Guacira Lopes. Currículo, gênero e sexualidade. In:

NECKEL, Jane Felipe; GOELLNER, Silvana Vilodre. Corpo, gênero e sexualidade: um debate contemporâneo na educação. Petrópolis: Vozes, 2003. p. 41-52.

. Pedagogias da sexualidade In: . $O$ corpo educado: pedagogias da sexualidade. Belo Horizonte: Autêntica, 1999. p. 7-34.

MONTADON, Cleopatre. As praticas educativas parentais e a experiência das crianças. Educação \& Sociedade, Campinas, v. 26, n. 91, p. 485-507, maio/ago. 2005. Disponível em: <http://www.scielo.br/pdf/es/v26n91/ a10v2691.pdf>. Acesso em: 01 jun. 2009.

SARMENTO, Manuel Jacinto Infância, exclusão social e educação como utopia realizável. Educação \& Sociedade, v. 23, n. 78, 2002. Disponível em: <http://www.scielo.br/scielo.php?script=sci arttext\&pid $=$ S010173302002000200015\&lng=\&nrm=iso\&tlng=>. Acesso em: 01 maio 2008.

. Visibilidade social e estudo da infância. In: VASCONCELOS, Vera Maria Ramos; SARMENTO, Manuel Jacinto. Infância (in)visível. Araraquara, SP: Junqueira \& Marin, 2007. p. 25-49.

TORRES, Cláudia Regina Vaz. Desconstruindo a identidade de "criminoso/a": o significado das ações educativas no sistema penitenciário. Dissertação (Mestrado em Educação) - Faculdade de Educação, Universidade Federal da Bahia, Salvador, 2004.

. Por um céu inteiro: crianças, educação e sistema prisional. 2010. 228 p.Tese (Doutorado em Educação)- Faculdade de Educação, Universidade Federal da Bahia, Salvador, 2010.

VIGOTSKI, Lev Semionovich. A formação social da mente: o 
desenvolvimento dos processos psicológicos superiores. São Paulo: Martins Fontes, 1998.

. A formação social da mente. São Paulo: Martins Fontes, 2002.

WACQUANT, Loic. As prisões da miséria. Rio de Janeiro: Zahar, 2001.

WOODWARD, Kathryn. Identidade e diferença: uma introdução teórica e conceitual. In: SILVA, Tomaz Tadeu (Org.). Identidade e diferença.

Petrópolis, RJ: Vozes, 2000. p. 7-72. 